\title{
STUDY OF DNA-DIETHYLSTILBOESTROL INTERACTION USING GRAPHENE-BASED THIN-FILM SENSOR AND UV-VIS SPECTROSCOPY
}

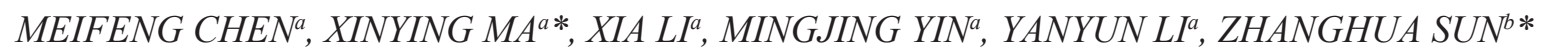 \\ ${ }^{a}$ School of Chemistry and Chemical Engineering, Heze University, Heze, China; ${ }^{b}$ Environmental monitoring central station of Heze, Heze, China.) \\ Correspondence A: Xinying Ma, School of Chemistry and Chemical Engineering, Heze, 274015, China.
}

\begin{abstract}
The graphene-modified glassy carbon electrode (Gr/GCE) was fabricated by casting graphene (Gr). Some electrochemical parameters for diethylstilbestrol (DES) detection, such as $\mathrm{pH}$, scan rate, and accumulation time were discussed. The interaction of DES with DNA at a Gr/GCE was studied by electrochemical method and factors influencing the interaction were optimized. Under the optimized conditions, the results revealed that the peak current decreased and the peak potential shifted to the positive side after adding DNA into the solution containing DES. We deduced that the interaction of DES with DNA mainly is intercalation. The interaction of DES with DNA was studied by ultraviolet and visible (UV-Vis) absorption spectroscopy. Also, with the addition of DNA, hyperchromic effect and small red shifts were observed in its UV-VIS spectra upon addition of DNA, results indicated that the DES molecule intercalated into the DNA, and the complex of DES-DNA was formed.
\end{abstract}

Key words: diethylstilboestrol; DNA; interaction; electrochemical method; UV-Vis spectroscopy

\section{INTRODUCTION}

Diethylstilbestrol (DES) was the first synthetic hormone. The molecular structure of DES is shown in scheme 1. Used primarily to prevent miscarriage and complications in pregnancy, DES was a common medication administered by doctors between 1938 and 1971[1]. However, researchers found that women who used DES themselves have a slightly increased risk of breast cancerapproximately 30 percent higher than that of women who did not take DES [24]. DES is now known to be an endocrine-disrupting chemical, one of a number of substances that interfere with the endocrine system to cause cancer, birth defects, and other developmental abnormalities. Therefore, the development of efficient analytical methods for its detection to prevent illegal usage is very important. Several analytical techniques have been used for the detection of DES, such as GC-MS [5-7], HPLC [8], LC-MS [9-12], electrochemical

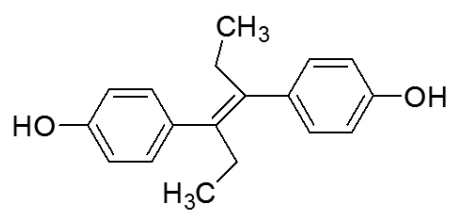

Scheme. 1 Molecular structure of Diethylstilbestrol

immunoassay [13] or chemiluminescence [14]. Since the concentration of DES in samples is extremely low, a preconcentration step (solid-phase extraction or solid/liquid phase microextraction), is usually required. However, the main problems associated with the use of sample preconcentration for the determination of DES are the lack of selectivity and the low recovery. To date, chemically modified electrodes have been applied for detection of DES [1519]. They are low-cost and usually do not require time consuming sample preparation.

In recent years, the interaction between biological materials and DNA has drawn great attention and has been extensively studied. Electrochemical technique $[20,21]$ is an effective way. However, the behavior of DES and its interaction with DNA at a graphene modified electrode have not been reported so far. Graphene electrochemical sensors are of growing interest nowadays, and they have been applied in various fields, such as detection of medicine, additive in food, contamination in environment and so on [22-24].

In this paper, the electrochemical behavior of DES and its interaction with DNA was successfully studied for the first time at the Gr/GCE. The interaction of DES with DNA was also studied by UV-vis spectroscopy. Also, with the addition of DNA, hyperchromic effect and small red shifts were observed in its UV-VIS spectra upon addition of DNA, results indicated that the DES molecule intercalated into the DNA, and the complex of DES-DNA was formed.

\section{2.- EXPERIMENTAL}

\subsection{Chemicals and Apparatus}

DES was bought from Chengdu Aikeda Chemical Reagent Co., Ltd (Chengdu, China). Calf thymus double-strand DNA (dsDNA) was purchased from Shanghai Yuanye Bio-Technology Co., Ltd (Shanghai, China). Graphene was synthesized from graphite powder according to our previously reported method [23]. Phosphate buffer solutions (PBS) were prepared by mixing disodium hydrogen phosphates and citric acid, both of which were purchased from Beijing Chemical Reagent Co. (China). All other reagents were of analytical grade and used as received.

Preparation of ssDNA stock solutions [21, 25]: The $2.0 \mathrm{mg} \mathrm{mL}^{-1} \mathrm{dsDNA}$ was immersed in heat water $\left(70 \sim 100^{\circ} \mathrm{C}\right)$ for $30 \mathrm{~min}$ and then cooled down rapidly with ice salt bath. After 30 minutes, the natural double-stranded DNA (dsDNA) had denaturated as single-stranded DNA (ssDNA).

Electrochemical experiments were carried out with a CHI-660E electrochemical workstation (Shanghai CH Instrument Company, China). UVVis spectra were recorded using a TU-1810 Spectrophotometer (Shimadzu) with $1-\mathrm{cm}$ path length quartz cuvettes.

\subsection{Preparation of Gr-GCE}

GCE was polished to a mirror-like surface with $0.05 \mu \mathrm{m}$ alumina slurry on microcloth pads, and sonicated in nitric acid $(1: 1, \mathrm{~V} / \mathrm{V})$, ethanol and water. Then, $0.006 \mathrm{~mL}$ of graphene stock solution $\left(0.5 \mathrm{mg} \mathrm{mL}^{-1}\right)$ was dropped onto the surface of the GCE, also followed by drying under an infrared lamp. The graphene and graphene-modied GCE were characterized by IR, SEM and TEM, which have been reported in our previous work [23].

\subsection{Experimental method}

2.3.1 Electrochemical method

A certain amount of DES solution or the mixture of DES and DNA, PBS $(\mathrm{pH}=4.0)$, distilled/deionized water were sequentially added into a cell. After stirring for $20 \mathrm{~s}$, the voltammograms were recorded at a $\mathrm{Cr} / \mathrm{GCE}$ in a certain potential range. The modified electrode was placed in PBS $(\mathrm{pH}=4.0)$ and scanned until no peak for reuse.

2.3.2 UV-Vis Method

$5.00 \mathrm{~mL}$ of PBS $(\mathrm{pH}=4.0), 5.00 \mathrm{~mL}$ of $1.00 \times 10^{-4} \mathrm{~mol} \mathrm{~L}^{-1}$ solution of DES and a certain amount of $2.0 \mathrm{mg} \mathrm{mL}^{-1}$ of calf thymus DNA solution were added into a $25 \mathrm{~mL}$ volumetric flask, and than PBS was used to reach the final volume of $25 \mathrm{~mL}$. The mixed solution was stored in the refrigerator at a temperature below $10{ }^{\circ} \mathrm{C}$ for one night and the UV -Vis spectra were recorded using a UV Spectrophotometer with $1-\mathrm{cm}$ path length quartz cuvettes in the wavelength range of $200-500 \mathrm{~nm}$

\section{3.- RESULTS AND DISCUSSION}

3.1 Electrochemical properties of DES at the Gr/GCE

The electrochemical properties of DES were studied on a bare GCE and a $\mathrm{Cr} / \mathrm{GCE}$ by $\mathrm{CV}$ method. The experimental results revealed that the oxidation current response of DES remarkably increased at the $\mathrm{Cr} / \mathrm{GCE}$ in $\mathrm{pH}$ 4.0 PBS (Seen in Figure 1), which suggested that the graphene has a high electrocatalytic 
activity toward the oxidation of DES. From the CVs of DES at the modified electrode, it was now known that $\mathrm{E}_{\mathrm{pa}}=0.477 \mathrm{~V}$ and $i_{\mathrm{pa}}=8.81 \times 10^{-5} \mathrm{~A}$.

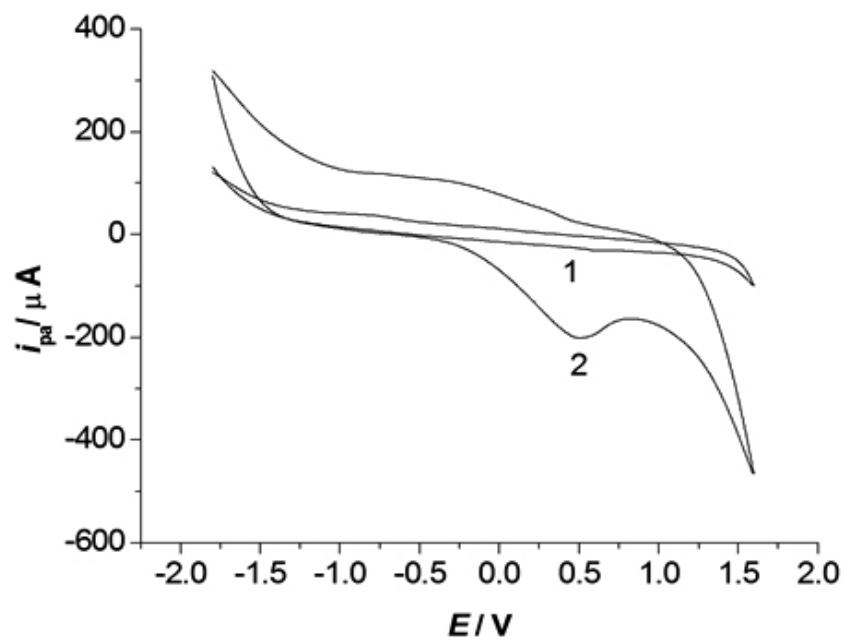

Fig. 1 Cyclic voltammograms (CVs) of $2.00 \times 10^{-5} \mathrm{~mol} \mathrm{~L}^{-1} \mathrm{DES}$ at a bare GCE (1) and a Gr/GCE (2). Scan rate: $100 \mathrm{mV} \mathrm{s}^{-1}$.

\subsection{Optimization of Conditions for DES Detection}

3.2.1 Influence of $\mathrm{pH}$

Influence of $\mathrm{pH}$ on the electrochemical signal was analyzed by linear sweep voltammetry in the $\mathrm{pH}$ range 2.2 to 8.0 . It was evident that the highes oxidation signal of DES was obtained at $\mathrm{pH}$ 4.0. Thus, $\mathrm{pH}=4.0 \mathrm{PBS}$ was chosen as the supporting electrolyte. Furthermore, the relationship between the peak potential $(E)$ and the solution $\mathrm{pH}$ can be described by the following equation (Fig. 2, Insert): $E_{\mathrm{pa}}=0.700-0.061 \mathrm{pH}, \mathrm{R}=0.9981$. The slope is 0.061 , which indicates that the number of electrons and protons involves in the reaction is equal according to Nernst Equation.

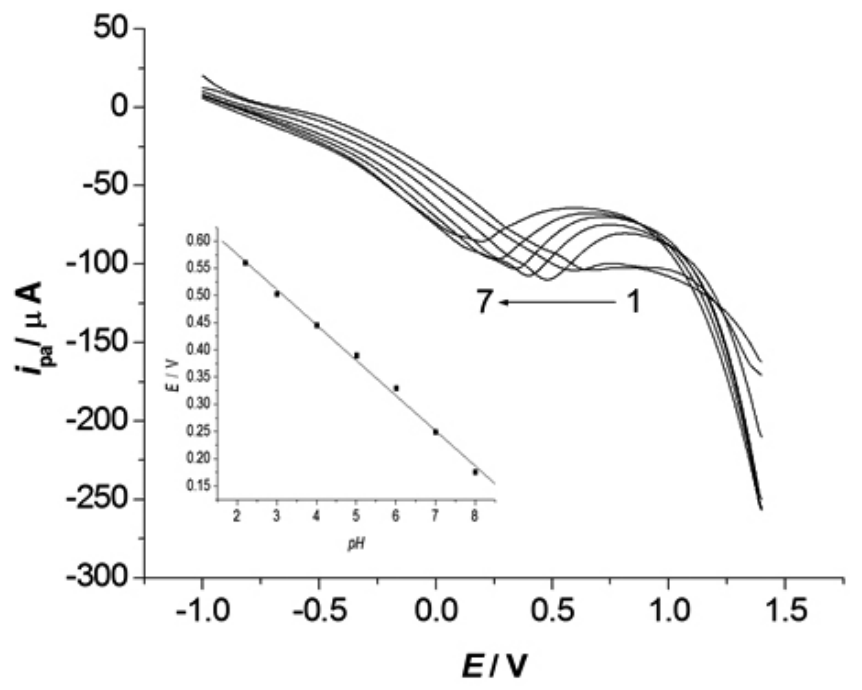

Fig. 2: CVs of $2.00 \times 10^{-5} \mathrm{~mol} \mathrm{~L}^{-1} \mathrm{DES}$ at a Gr-GCE at different $\mathrm{pH}$ (from 1 to 7 ): $2.2,3.0,4.0,5.0,6.0,7.0$, and 8.0, respectively. Inset is the plot of oxidation peak currents versus $\mathrm{pH}$.

\subsubsection{Influence of scan rate}

The influence of scan rate was investigated. Electrochemical signal was achieved by applying various scan rates of 20,40, 60, 80,100, 120, 140 and 160 $\mathrm{mV} \mathrm{s}^{-1}$ and the results were shown in Figure 3. The current response increased with the increasing of scan rate. As presented in Figure 3 (Insert), a linear relationship between the response signal and scan rate of DES was obtained from 20 to $160 \mathrm{mV} \mathrm{s}^{-1}$ with a correlation coefficient of 0.9940 . These show that it is an adsorption process of electrochemical behaviors of DES at the $\mathrm{Gr}$ /
Nano-Au/GCE by the following equation: $i=0.700-0.061 \mathrm{v}$. As a result, a good signal was obtained when the scan rate is $100 \mathrm{mV} \mathrm{s}^{-1}$. Therefore, $100 \mathrm{mV}$ $\mathrm{s}^{-1}$ was used as the scan rate in our work.

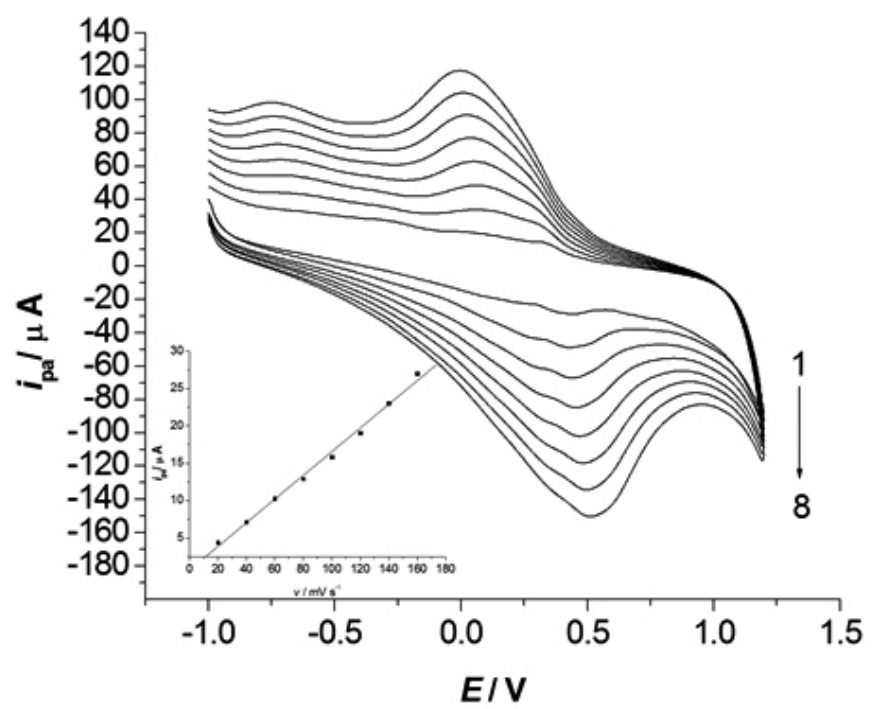

Fig. 3: CVs of $2.00 \times 10^{-5} \mathrm{~mol} \mathrm{~L}^{-1} \mathrm{DES}$ at a Gr-GCE at different scan rate. Each of the numbers from 1 to 8 corresponds to a scan rate of 20,40,60, 80 , $100,120,140$ and $160 \mathrm{mV} \mathrm{s}^{-1}$, respectively. Inset is the plot of redox peak currents of CGA versus scan rates.

3.3 The interaction DES with DNA and comparisons of the interaction dsDNA and ssDNA with DES

In order to assess the different interaction strengths of DES with both ssDNA and dsDNA, the interaction of dsDNA and ssDNA with DES was studied electrochemically by using $\mathrm{CV}$ at $\mathrm{Gr} / \mathrm{GCE}$ in PBS (pH 4.0) (Seen in Figure 4). The results revealed that the peak current decreased and the peak potential shifted positively after adding either dsDNA or ssDNA into the solution containing DES. We deduced that the interaction of DES with DNA mainly is intercalation [26].

But, the peak potential of the DES solution containing dsDNA is more positive than that of the DES solution containing ssDNA. Furthermore, the signals were found the signal decreased significantly than that with ssDNA. This is probably because dsDNA have the double helix structure, DES can be embedded into the double helix structure and the complex of DES-dsDNA was formed. On the contrary, ssDNA does not have a double helix structure and intercalation relatively weak. Therefore, dsDNA was used in our work.

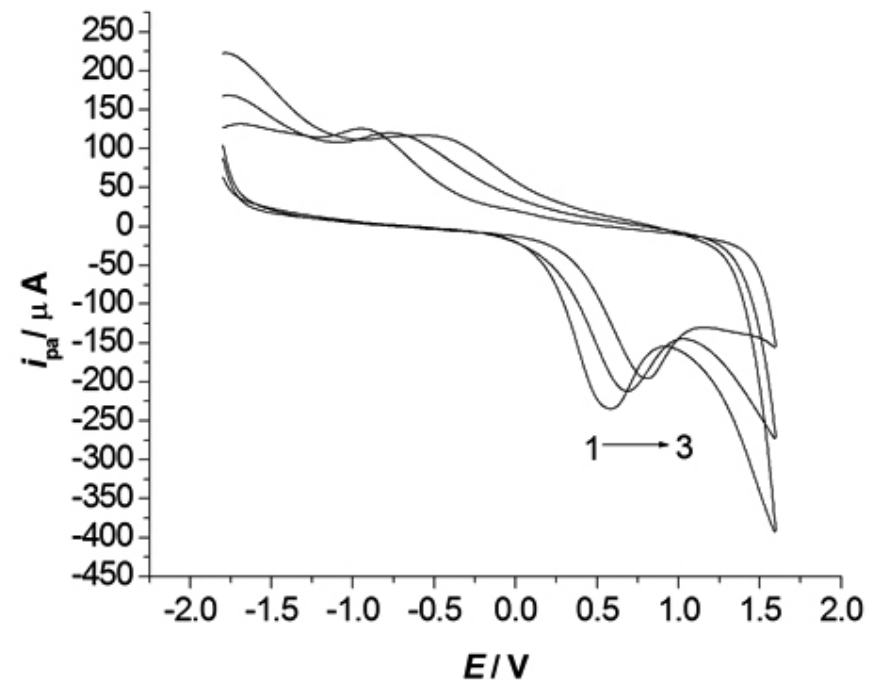

Fig. 4: CVS of DES (curve 1), the mixture of CGA and ssDNA DNA (curve 2), and the mixture of DES and dsDNA (curve 3 ) in pH 4.0 at a Gr-GCE. 
3.4 Optimality Conditions of electrochemical method

Different effect factors, such as time, temperature, and DNA concentration were determined in our work

3.4.1 Effects of interaction time

The effect of interaction time on the interaction between DES and dsDNA was studies from 5 to $45 \mathrm{~min}$. The peak current decreases gradually with the increase of the reaction time and attains a minimum value after 20 minutes.

3.4.2 Effect of temperature

The effect of temperature was examined over the range of 25 to $60^{\circ} \mathrm{C}$. It was found that the peak current decreased and the peak potential shifted to more positive values with increasing temperature. When the temperature is higher than $45^{\circ} \mathrm{C}$, the peak current is basically stable. So, the experiment was carried out at $45^{\circ} \mathrm{C}$.

\subsection{Effect of DNA concentration}

The effect of DNA concentration over the range $0.005 \sim 0.06 \mathrm{mg} \mathrm{mL}^{-1}$ on the peak current of DES with stirring for 20 minutes at $45^{\circ} \mathrm{C}$ was examined by using the CV method. It was found that the peak current decreased and the peak potential shifted to the positive side with an increase in the amount of DNA as shown in Figure 5. We also deduced that there existed the interaction between DES and DNA [26].

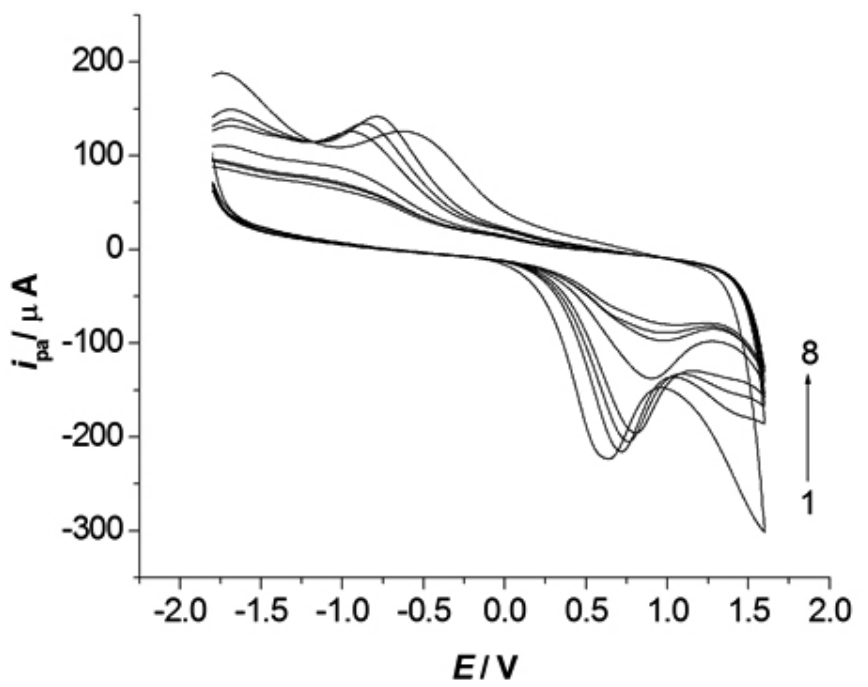

Fig. 5: Cvs of $2.00 \times 10^{-5} \mathrm{~mol} \mathrm{~L}^{-1}$ DES containing different concentrations of DNA at the Gr-GCE. Each of the letters from 1 to 8 corresponds to a concentration of DNA: $0.005,0.008,0.010,0.015,0.020,0.040,0.050$ and 0.060 , respectively (in $\mathrm{mg} \mathrm{mL}^{-1}$ ).

\subsection{Determination of $\mathrm{UV}-\mathrm{V}$ is absorption spectroscopy}

In this part of the study, UV-Vis absorption spectroscopy was further employed to examine the interaction of DES with dsDNA. When dsDNA was added to DES solution, the absorption peak increased, that was hyperchromic effect. We then deduced there were some changes in absorbance and the position of the band would red shift when DES interacts with DNA. The possible reasons to explain why the spectral have some effects may be that $[27,28]$ it can cause an energy decrease, and a decrease of the $\pi \rightarrow \pi^{*}$ transition energy when the empty $\pi^{*}$-orbital of the small molecule couples with the $\pi$-orbital of the DNA base pairs. It shows that their electron clouds affected and overlapped each other statically to form an association. So, the binding mode between DES and DNA was electrostatic interaction [29-31]. With the increase of the concentration, the absorption peak shifted towards longer wavelengths, which is red-shifted. It indicates that new function group was produced after adding DNA solution into the DES solution and there existed the intercalation binding between DES and DNA.

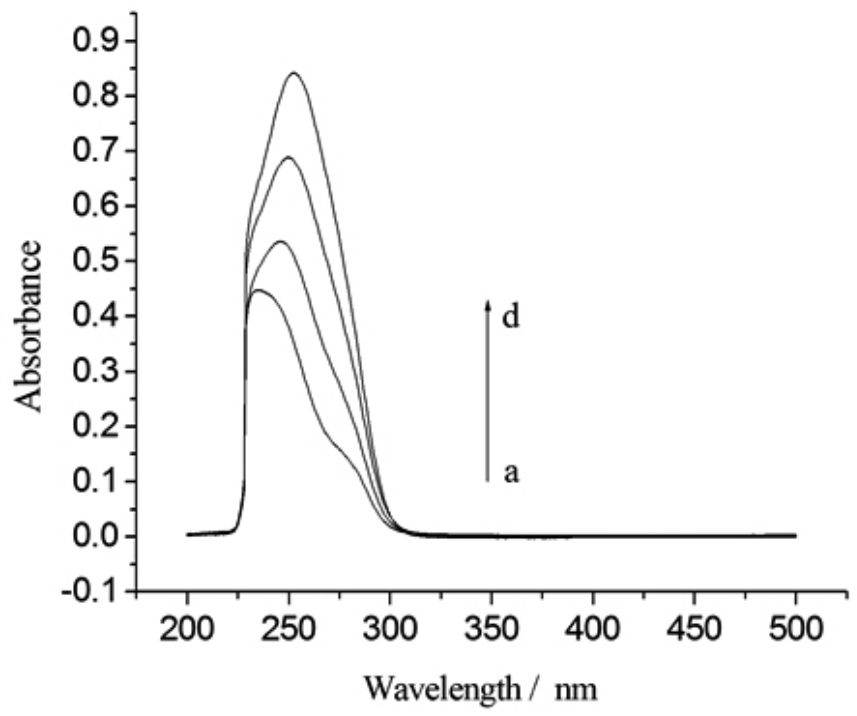

Fig. 6: UV-Vis spectra of $2.00 \times 10^{-5} \mathrm{~mol} \mathrm{~L}^{-1}$ DES containing different concentrations of DNA at the Gr-GCE. Each of the letters from a to $d$ corresponds to a concentration of DNA: $0.000,0.005,0.008$ and 0.010 , respectively (in $\mathrm{mg} \mathrm{mL}^{-1}$ )

\section{CONCLUSIONS}

The interaction of DES with DNA has been studied in two ways in PBS on the surface of Gr/GCE. DES could interact with DNA and formed a complex. Under the optimized conditions, the results revealed that the peak current decreased and the peak potential shifted to the positive side after adding DNA into the solution containing DES. Based on this, we deduced that the interaction of DES with DNA mainly was intercalation. The interaction of DES with DNA was studied by UV-vis spectroscopy. Also, with the addition of DNA, hyperchromic effect and small red shifts were observed in its UVVIS spectra upon addition of DNA, results indicated that the DES molecule intercalated into the DNA, and the complex of DES-DNA was formed.

\section{ACKNOWLEDGEMENTS}

The work was supported by the Natural Science Foundation Committee of Shandong Province, China (ZR2014BL020), the Project of Shandong Province Higher Educational Science and Technology Program (J14LC55) and the Scientific Research Foundation of Heze University (XY14KJ02).

\section{REFERENCES}

[1] P. White, H. Hunt, J. Clin. Endocrinol. 3, 500, (1943)

[2] A. L. Herbst, H. Ulfelder, D. C. Poskanzer, The New England Journal of Medicine 284, 878, (1971).

[3] L. Titus-Ernstoff, E. E.Hatch, R. N. Hoover, J. Palmer, E. R. Greenberg, W. Ricker, R. Kaufman, K. Noller, A. L. Herbst, T. Colton, P. Hartge, Br. J. Cancer. 84, 126, (2001)

[4] L. Titus-Ernstoff, R. Troisi, E. E. Hatch, J. R. Palmer, L. A. Wise, W. Ricker, M. Hyer, R. Kaufman, K. Noller, W. Strohsnitter, A. L.Herbst, P. Hartge, R. N. Hoover, Br. J. Cancer., 95,107, (2006)

[5] J. B. Quintana, J.Carpinteiro, I. Rodríguez, R. A. Lorenzo, A. M. Carro, R. Cela, J. Chromatogr. A 1024, 177, (2004)

[6] A. Prieto, A. Vallejo, O. Zuloaga, A. Paschke, B. Sellergen, E. Schillinger, S. Schrader, M. Moder, Anal. Chim. Acta 703, 41, (2011)

[7] K. Sanfilippo, B. Pinto, M. P. Colombini, U. Bartolucci, D. Reali, J. Chromatogr. B 878,1190, (2010)

[8] X.P He, X.Q Mei, J.T Wang, , Z.L, L.J Tan, W. Wu, Mar. Pollut. Bull $102,142-147,(2016)$

[9] Q. Xu, M. Wang, S. Q. Yu, Q. Tao, M. Tang, Analyst 136,5030, (2011)

[10] S. Rodriguez-Mozaz, M. J. Lopez de Alda, D. Barcelo, Anal. Chem. 76, 6998, (2004)

[11]X. B. Chen, Y. L. Wu, T. Yang, J. Chromatogr. B, 879,799, (2011)

[12]K. Mitani, M. Fujioka, H. Kataoka, J. Chromatogr. A 1081, 218, (2005) 
[13]S. Liu, Q. Lin, X. M. Zhang, X. R. He, X. R. Xing, W. J. Lian, J. Li, M. Cui, J. D. Huang, Sens. Actuators B, 166/167, 562, (2012)

[14] Q. L. Zhang, J. Li, T. T Ma, Z. T. Zhang, Food Chem.111, 498, (2008)

[15] J. J. Fei, X. Q. Wen, L. H. Yi, F. Ge, Y. Zhang, M. H. Huang, X. M.Chen, J. Appl. Electrochem. 38, 1527, (2008)

[16]C. M. Yu, W. Y. Ji, Y. D. Wang, N. Bao, H. Y. Gu, Nanotechnology 241 , $15502,(2013)$

[17] K. M. Qu, X. Z. Zhang, Z. L. Lv, M. Li, Z. G. Cui, Y. Zhang, B. J. Chen, S. S. Ma, Q. Kong, Int. J. Electrochem. Sci. 7, 1827, (2012)

[18]X. Y. Ma, M. F.Chen, Sens. Actuators B 215, 445, (2015)

[19] L.T Hu, Q. Cheng, D.C. Chen , M. Ma , K.B. Wu, J. Hazard. Mater. $283,157-163,(2015)$

[20]X. L. Wang, J. J. Li, T. Wang, Z. Y. Yu, Ionics 21,1105, (2015)

[21]F. Li, J. Q. Li, Y. Feng, L. M. Yang, Z. F. Du, Sensor Actuat. B-Chem. $157,110,(2011)$
[22]Y. R. Kim, S. Bong, Y. J. Kang, Y. Yang, R. K. Mahajan, J. S. Kim, H. Kim, Biosens. Bioelectron. 25, 2366, (2010)

[23] M. F. Chen, X. Y. Ma, X. Li, J. Solid State Electrochem.16, 3261, (2012)

[24]X.Y. Ma, M. Y. Chao, M. F. Chen, Russ. J. Electrochem. 50, 154, (2014)

[25]B. X. Ye, C. H. Wang, A. H. Jing, J. Chin. Chem. Soc. 50, 457, (2003)

[26] M. T. Carter, M. Rodriguez, A. J. Bard, J. Am. Chem. Soc.111, 8901, (1989)

[27]L. Fotouhi, A.B. Hashkavayi, and M.M. Heravi, Int. J. Bio.l Macromo. $53,101,(2013)$

[28]M. Aslanoglu, Anal, Sci. 22, 439, (2006)

[29] C. V. Kumar, E. H. Asuncion, J. Am. Chem. Soc. 115, 8541, (1993 )

[30] A. M. Nowicka, E. Zabost, M. Donten, Z. Mazerska, Z. Stojek, Bioelectrochemistry, 70, 440, (2007)

[31]Y. N. Ni, M. Wei, S. Kokot, Int. J. Biol.Macromol. 49, 622, (2011) 